University of Nebraska - Lincoln

DigitalCommons@University of Nebraska - Lincoln

Sociology Department, Faculty Publications

Sociology, Department of

$3-2000$

\title{
The Effects of Early Sexual Abuse on Later Sexual Victimization Among Female Homeless and Runaway Adolescents
}

Kimberly A. Tyler

University of Central Florida, kim@ktresearch.net

Dan R. Hoyt

University of Nebraska-Lincoln, dhoyt2@unl.edu

Les B. Whitbeck

lowa State University, Iwhitbeck2@unl.edu

Follow this and additional works at: https://digitalcommons.unl.edu/sociologyfacpub

Part of the Sociology Commons

Tyler, Kimberly A.; Hoyt, Dan R.; and Whitbeck, Les B., "The Effects of Early Sexual Abuse on Later Sexual Victimization Among Female Homeless and Runaway Adolescents" (2000). Sociology Department, Faculty Publications. 33.

https://digitalcommons.unl.edu/sociologyfacpub/33

This Article is brought to you for free and open access by the Sociology, Department of at DigitalCommons@University of Nebraska - Lincoln. It has been accepted for inclusion in Sociology Department, Faculty Publications by an authorized administrator of DigitalCommons@University of Nebraska - Lincoln. 
Published in Journal of Interpersonal Violence 15:3 (March 2000), pp. 235-250.

Copyright (C) 2000 Sage Publications, Inc. Used by permission.

http://jiv.sagepub.com/cgi/reprint/15/3/235

A version of this article was presented at the Midwest Sociological Society Meetings in Kansas City, April 1998. This article is based on research supported by a grant from the National Institute of Mental Health (MH50140), Les B. Whitbeck principal investigator.

\title{
The Effects of Early Sexual Abuse on Later Sexual Victimization Among Female Homeless and Runaway Adolescents
}

\author{
Kimberly A. Tyler, University of Central Florida \\ Dan R. Hoyt, Iowa State University \\ Les B. Whitbeck, Iowa State University
}

\begin{abstract}
Based on risk amplification and victimization theories, path analysis was used to investigate the effect of early sexual abuse on later sexual victimization among 361 female homeless and runaway adolescents in four midwestern states. Results indicated that early sexual abuse in the home had a positive direct effect on sexual victimization of adolescents on the streets. Early sexual abuse also increased the likelihood of later sexual victimization indirectly by increasing the amount of time at risk, deviant peer associations, and incidents of survival sex. Young women who leave dysfunctional and disorganized homes often characterized by abuse continue on negative developmental trajectories once they reach the streets. The social context of street life puts these adolescents in close proximity to potential offenders and exposes them to crime and criminals. The combination of a negative developmental trajectory and the high-risk street environment increases these young women's chances of being sexually victimized.
\end{abstract}

Negative developmental outcomes have been reported for adolescents with a history of sexual abuse. Depression, poor self-esteem, substance abuse, inappropriate sexual behavior, suicidal ideation, running away, and prostitution are just some of the effects that have been noted (Beitchman, Zucker, Hood, da Costa, \& Akman, 1991; Browne \& Finkelhor, 1986; Silbert \& Pines, 1981). Runaways, in particular, tend to suffer from much 
higher rates of childhood sexual abuse compared to other adolescents (cf. Bayatpour, Wells, \& Holford, 1992; Janus, McConnack, Burgess, \& Hartman, 1987). Furthermore, females are more likely to be sexually abused compared to males (Finkelhor, 1993; Finkelhor \& Dziuba-Leatherman, 1994). Runaways who have experienced early family abuse are at risk for revictimization on the streets (Whitbeck, Hoyt, \& Ackley, 1997a). Research demonstrates that the abuse indirectly influences street victimization by increasing young women's ties to deviant peers who may facilitate experimentation with various sorts of deviant behaviors (Simons \& Whitbeck, 1991; Whitbeck \& Simons, 1990, 1993). Furthermore, the social context of street life also may increase the probability of sexual victimization among female homeless and runaway adolescents.

\section{Rates of Early Childhood Sexual Abuse}

Although there are no reliable statistics on how many cases of childhood sexual abuse occur each year, it is estimated that 1 in 4 girls and 1 in 10 boys will suffer from victimization (Finkelhor, 1993). The risk for sexual abuse rises in preadolescence, and girls are at higher risk compared to boys. Statistics on childhood sexual abuse only exist for those cases that are reported to child protection agencies or law enforcement offices. According to Finkelhor (1994), the actual number of cases being reported to child abuse authorities are 2.4 cases per 1,000.

Although only $15 \%$ of child sexual abuse cases have been substantiated (Finkelhor, 1994), the actual number of cases are expected to be much higher because sexual abuse is underreported by both male and female children (Becker, 1988). Retrospective reports of rates of childhood sexual abuse range anywhere from $20 \%$ (Fleming, Mullen, \& Bammer, 1997) to a high of $60 \%$ (Peters, 1988). Studies done on adolescents and youths report a range of percentages similar to those found in adult retrospective reports. Bayatpour and associates (1992) reported that almost 15\% of teens they surveyed had been sexually abused, whereas Kellogg and Hoffman (1997) found much higher rates of sexual victimization among females (54\%) compared to males (15\%). Although the estimated rates vary across studies, the clear pattern is high rates of abuse whether retrospective reports or youth samples are used.

Studies find even higher rates of abuse among homeless and runaway adolescents. Some research revealed that more than $50 \%$ of adolescents studied reported being sexually abused (Janus et al., 1987; Silbert \& Pines, 1981). Moreover, gender differences revealed that females experienced much higher rates of sexual abuse (73\%) compared to their male counterparts (38\%; McCormack, Janus, \& Burgess, 1986). 


\section{The Effects of Early Sexual Abuse}

The negative developmental outcomes that adolescents experience as a result of early childhood sexual abuse have been divided into both shortand long-term consequences. Short-term effects of childhood sexual abuse included depression, low self-esteem, and suicidal behavior and/or ideation. Other commonly reported behavior among sexually abused adolescents included running away, substance abuse, and promiscuity (Beitchman et al., 1991). In addition to those short-term effects listed above, fear, anger, hostility, and inappropriate sexual behavior also have been noted as other possible short-term consequences (Browne \& Finkelhor, 1986). Long-term effects of childhood sexual abuse included promiscuity, depression, difficulty trusting others, self-destructive behavior, and revictimization (Beitchman et al., 1992; Browne \& Finkelhor, 1986).

\section{Risk Amplification Model}

This study views the transition of adolescents from home to the street from a risk amplification model (Whitbeck, Hoyt, \& Yoder, 1999). Based on life course developmental theory (Elder, 1997) and social interaction theory (Patterson, 1982), this model holds that runaway adolescents often leave dysfunctional and disorganized homes where street experiences amplify negative developmental effects originating in the family, and these developmental problems set the stage for later victimization.

Patterson (Patterson, Dishion, \& Bank, 1984) has argued that coercive families provide "basic training" for antisocial behaviors that are the result of continuous failure on the part of the parents to use effective discipline techniques in controlling coercive exchanges between family members. Through this training, the child learns to control other family members through coercion, and these interaction styles are generalized into other contexts. These coercive and abusive behaviors become coping styles that are carried with the adolescent into peer interactions, which results in rejection by normal peer groups (Patterson et al., 1984; Patterson, DeBaryshe, \& Ramsey, 1989). As adolescents leave their dysfunctional and/ or abusive families, interaction patterns learned at home are carried into early independence. The basic training for antisocial behavior in the family now becomes "advanced training" on the streets. The combination of antisocial behavior and rejection by conventional peers leads adolescents to form ties with deviant peer groups, which are important for explaining the adolescents' subsequent involvement in risky, deviant behaviors (Whitbeck et al., 1999). 
Once adolescents are on the street, the social environment in which they interact becomes significant. The effects of risks and abuse that were experienced in the home become amplified on the street (Whitbeck et al., 1999). Victimization theories, which define the social context in which crime occurs, are useful for explaining how the social environment in which runaway adolescents interact on a day-to-day basis puts them at risk for victimization. Living on the streets exposes runaways to both criminals and potential offenders. Exposure to crime as well as the fact that runaways are easily preyed on because of their age increases their risk for victimization. Specifically, lifestyle-exposure theory (Hindelang, Gottfredson, \& Garofalo, 1978) and routine activity theory (Cohen \& Felson, 1979) argue that the lifestyles and daily routines of people's everyday lives are related to differential exposure to dangerous places and people, which creates the potential for crime opportunities and therefore increased victimization.

In summary, early life exposure to dysfunctional homes places these youth on trajectories for early independence. Subsequently, the lifestyles and daily routines in which many of these runaways engage on a regular basis to survive put them in a particular social environment where they are exposed to dangerous people and places. Existing in such an environment and lacking conventional ties, these young people are at increased risk of being sexually victimized.

\section{Sexually Abused Adolescents on the Streets}

A fully recursive model was hypothesized to investigate the cumulative effects of caretaker sexual abuse (see Figure 1). It was expected that early sexual abuse would be negatively associated with the age at which the adolescent first left home (Arrow A). Childhood sexual abuse typically occurs between 8 and 12 years of age (Finkelhor, 1984); therefore, children who have been abused sexually are likely to run at earlier ages. Early sexual abuse was predicted to increase the total time the adolescent spent in unsupervised settings (Arrow B). A history of family abuse has been found to be associated with the amount of time that adolescents spend out on their own (Janus et al., 1987; Whitbeck et al., 1999). Furthermore, an abusive family background was predicted to increase the likelihood of associating with friends who sold sex (Arrow C). Research demonstrates that children from abusive backgrounds drift into associations with deviant peers (Patterson, 1982; Whitbeck et al., 1997a). Direct effects also were hypothesized for early sexual abuse on number of different sexual partners, sex trading, and alcohol and/or drug use (Arrows D). Numerous studies have linked abuse by parents or caretakers to numerous sexual part- 


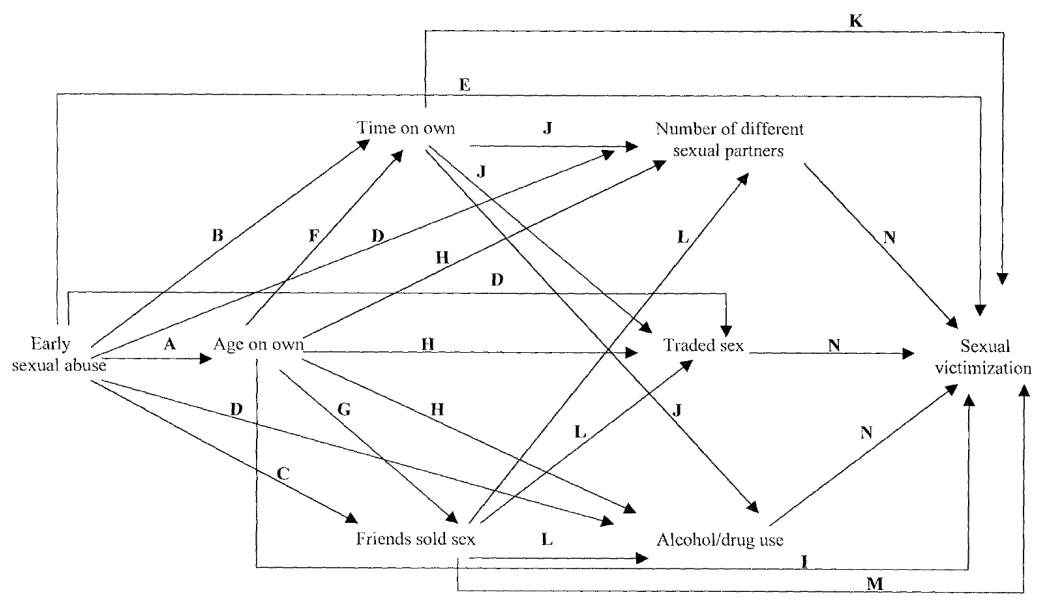

Figure 1. Hypothesized Model for Female Sexual Victimization

ners (Bagley \& Young, 1987), sex trading (Silbert \& Pines, 1981; Weisberg, 1985; Widom \& Kuhns, 1996), and substance use (Dembo et al., 1989). Finally, early sexual abuse was hypothesized to directly influence sexual victimization (Arrow E). Adolescents from abusive backgrounds often experience emotional problems such as depression and poor self-esteem (Beitchman et al., 1991; Morrow \& Sorell, 1989), which may make them more vulnerable targets on the streets.

It was expected that adolescents who ran for the first time at an early age would have spent more time in unsupervised living arrangements (Arrow F) and associated with friends who sold sex (Arrow G). Spending time on the street has been found to be associated with deviant peers and engaging in criminal street networks (Hagan \& McCarthy, 1997). Furthermore, it was expected that age on own would be associated with number of different sexual partners, sex trading, and substance use (Arrows $\mathrm{H}$ ). Young people who are on the streets from an early age are likely to have greater exposure to risky behaviors as well as crime and criminals. Finally, being on the street at an early age increases exposure and risk. Following this, it was expected that age on own would be associated with sexual victimization (Arrow I).

Because it increases the amount of time at risk for participation in risky behaviors, a positive association was predicted between total time on own and number of different sexual partners, sex trading, and substance use (Arrows J). Being on the street also exposes these young people to dangerous people and places; therefore, it was expected that time on own would 
positively predict sexual victimization (Arrow K). Associating with deviant peers who sell sex was expected to positively predict number of different sexual partners, sex trading, and substance use (Arrows L). Furthermore, associating with friends who sell sex is likely to increase the adolescents' chances of interacting with sexually violent customers. As such, a positive association was expected between friends selling sex and sexual victimization (Arrow M).

Finally, based on other studies of victimization among runaway and homeless adolescents (McCarthy \& Hagan, 1992; Whitbeck \& Simons, 1990, 1993; Whitbeck et al., 1997a), high-risk behaviors (numerous sexual partners, sex trading, substance use) were expected to increase the risk for sexual victimization while on the street (Arrows N).

\section{Method}

\section{Participants}

The sample is from the Midwest Homeless and Runaway Adolescent Project (MHRAP), a four-state study of runaway adolescents from Missouri, Iowa, Nebraska, and Kansas. Of the total 602 adolescents that were interviewed, only the females $(n=361)$ were used for these analyses. Young people were interviewed directly on the streets, in shelters, and in dropin centers by outreach workers who were trained youth workers with considerable experience interviewing and interacting with this group of young people. They were very familiar with local street cultures and were already known and trusted by many of the runaways. Respondents were recruited as part of the participating agencies' regular intake and outreach programs. Agencies were selected for participation in the study based on having an existing street outreach program in addition to shelter and/or transitional living facilities. All but one of the study agencies had a street outreach van. This agency had an inner-city drop-in center that catered to street youth. There were a total of six agencies: two in St. Louis and one each in Kansas City, Wichita, Lincoln, and Des Moines.

Upon initial contact, the interviewers read the consent statement to the youth and explained the study procedures. Respondents were informed that they could refuse participation, refuse single questions, or stop participating in the interview at any time. They also were informed that reports of abuse by adults must be reported by law and that steps would be taken for their protection in the event of disclosure of plans to harm themselves. Adolescents signed the consent form prior to starting the interview. The adolescents were not living under parental supervision at the 
time of the interview and were considered emancipated. Referral and support services were offered to youths on the street and provided to youths in shelters by the agencies as part of their outreach programs. Agreeing to be interviewed was not a precondition for any of the services the agencies provided. Interviews lasted about $1 \frac{1 / 2}{2}$ hours. A snack was provided during a break in the interview process, and the adolescents each received $\$ 15$ for participation.

Response rates ranged from a low of $71 \%$ to a high of $100 \%$. The average response rate across all agencies was $93 \%$. Although response rates were high, there were few street intercepts that may have resulted in a bias selection process because the harder core adolescents who do not use shelters may have been omitted.

Of the 361 females who were interviewed, the majority were White (64\%) or African American (22\%); 4\% were Hispanic; and the remaining $10 \%$ were either Asian, American Indian, biracial, or multiracial. These young women ranged in age from 12 to 22 years, with a mean of 16 years. Many of these runaways were on their own for the first time at very young ages. The median age at first time on own was 14 years. In addition, these young women had spent between 1 day and 7.1 years on the street, with a median of 13 days. Of the young women, $32 \%$ were sexually abused while still living at home, and $21 \%$ of all females were sexually victimized while on the street. Approximately $11 \%$ had experienced both early sexual abuse and street sexual victimization.

\section{Measures}

"Early sexual abuse" consisted of two items that asked the respondents how often a parent or guardian had ever made a verbal request for sexual activity or had ever forced them to engage in sexual activity while living at home. The two items were summed and dichotomized such that $0=$ "It had never happened," and 1 = "It had happened at least once." This item was adapted from Whitbeck and Simons (1990). The bivariate correlation between these two items was .80 .

"Age on own" was a single item that asked the adolescents how old they were when they left home and were on their own for the first time.

"Time on own" was measured by the total amount of time the respondents had been either on the street or in unsupervised living arrangements (e.g., living with friends, having an apartment) since living away from home.

"Friends sold sex" was measured using four items that asked the young women if any of their close friends had ever solid sexual favors for money 
or drugs and/or food or shelter and if they knew anyone who had traded sex for food or shelter and/or money or drugs since being on the street. Response categories were 0 (no) and 1 (yes). Cronbach's alpha for friends selling sex was .83 for females.

"Number of different sexual partners" was a single item that asked the participants to indicate the total number of different people they had had sex with in the past 12 months.

"Trading sex" was assessed using two items for which the respondents were asked if they had ever traded sex for food or shelter and if they had ever traded sex for money or drugs since being on the street. The two items were summed and then dichotomized such that those who had never traded sex were coded as 0 and those who had traded sex were coded as 1. The bivariate correlation between these two items was .56.

"Alcohol/drug use" was measured using 11 items in which adolescents were asked about frequency of use of beer, hard liquor, marijuana, cocaine, amphetamines, and other hard drugs during the past 12 months. Each item was dichotomized so that response categories were 0 (no) and 1 (yes), and then each of the 11 dichotomized items were summed into a single scale. Response categories ranged from 0 (never) to 11 (many times). Cronbach's alpha for this measure was .81 for females.

"Sexual victimization" while on the street consisted of two items for which the young women were asked if they had ever been forced to do something sexual and if they had been sexually assaulted or raped (adapted from Whitbeck \& Simons, 1990). Due to skewness, response categories were summed and then dichotomized into 0 (no) and 1 (at least once). The bivariate correlation between these two variables was .80 .

\section{Procedure}

A path model that focused on risk factors associated with sexual victimization while on the streets among female homeless and runaway adolescents was estimated using generalized least squares (Jöreskog \& Sörbom, 1993). Thus, each of the standardized path coefficients $\beta$ for arrows leading to a specific dependent variable were estimated simultaneously with all other variables predicted to influence the measure in question. This is a fully saturated model that fits the data perfectly; therefore, fit indices are not reported. Independent variables included early sexual abuse at home, age on own, time on own, friends selling sex, number of different sexual partners, trading sex, and alcohol/drug use. Due to listwise deletion, the sample was reduced to 333 cases for these analyses. 
Table 1. Correlation Matrix for Female Sexual Victimization $(N=333)$

\begin{tabular}{lcccccccc}
\hline & 1 & 2 & 3 & 4 & 5 & 6 & 7 & 8 \\
\hline 1. Early sexual abuse & & & & & & & & \\
2. Age on own & $-.21^{* *}$ & & & & & & & \\
3. Time on own & $.12^{*}$ & $-.19^{* *}$ & & & & & & \\
4. Friends sold sex & $.14^{* *}$ & $-.13^{*}$ & $.17^{* *}$ & & & & & \\
5. Different sex partners & .04 & -.06 & .10 & $.19^{* *}$ & & & & \\
6. Traded sex & $.11^{*}$ & $-.14^{*}$ & $.14^{*}$ & $.31^{* *}$ & $.37^{* *}$ & & & \\
7. Alcohol/drug use & .10 & -.10 & $.16^{* *}$ & $.22^{* *}$ & $.30^{* *}$ & $.28^{* *}$ & & \\
8. Sexual victimization & $.21^{* *}$ & $-.12^{*}$ & $.18^{* *}$ & $.35^{* *}$ & $.19^{* *}$ & $.29^{* *}$ & $.25^{* *}$ & \\
M & .310 & 13.58 & 3.90 & 1.10 & 2.53 & .066 & 3.02 & .200 \\
SD & .463 & 2.46 & 1.82 & 1.43 & 4.59 & .248 & 2.38 & .401 \\
\hline
\end{tabular}

${ }^{*} p<.05,{ }^{* *} p<.01$

\section{Results}

Table 1 shows the correlation matrix for the variables included in these analyses. Early sexual abuse was significantly associated with age on own $(r=-.21)$ and time on own $(r=.12)$, suggesting that victims of sexual abuse were more likely to have run away from home at earlier ages and to have spent more time on the streets or in unsupervised living arrangements. Young women with a history of sexual abuse engaged in survival sex $(r=$ $.11)$, had friends who traded sex $(r=.14)$, and reported being sexually victimized while on the street $(r=.21)$. Those who left home at a young age spent more time on their own $(r=-.19)$, traded sex $(r=-.14)$, had friends who sold sex $(r=-.13)$, and reported being sexually victimized $(r=-.12)$. The more time spent on the street or in unsupervised living arrangements, the more likely adolescents were to have engaged in survival sex $(r=.14)$, affiliated with friends who sold sex $(r=.17)$, used large amounts of alcohol and/or drugs $(r=.16)$, and reported being sexually victimized $(r=$ .19). Those who associated with deviant peers who had sold sex reported multiple sex partners $(r=.19)$, selling sex $(r=.31)$, high rates of substance use $(r=.22)$, and being victims of sexual assault $(r=.35)$. Engaging in sexual intercourse with multiple partners was associated with survival sex ( $r$ $=.37)$, high rates of substance use $(r=.30)$, and being sexually victimized $(r=.19)$. Female adolescents who engaged in survival sex reported higher rates of alcohol and/or drug use $(r=.28)$ and sexual assault $(r=.29)$. Finally, substance use was significantly associated with sexual victimization on the street $(r=.25)$. 


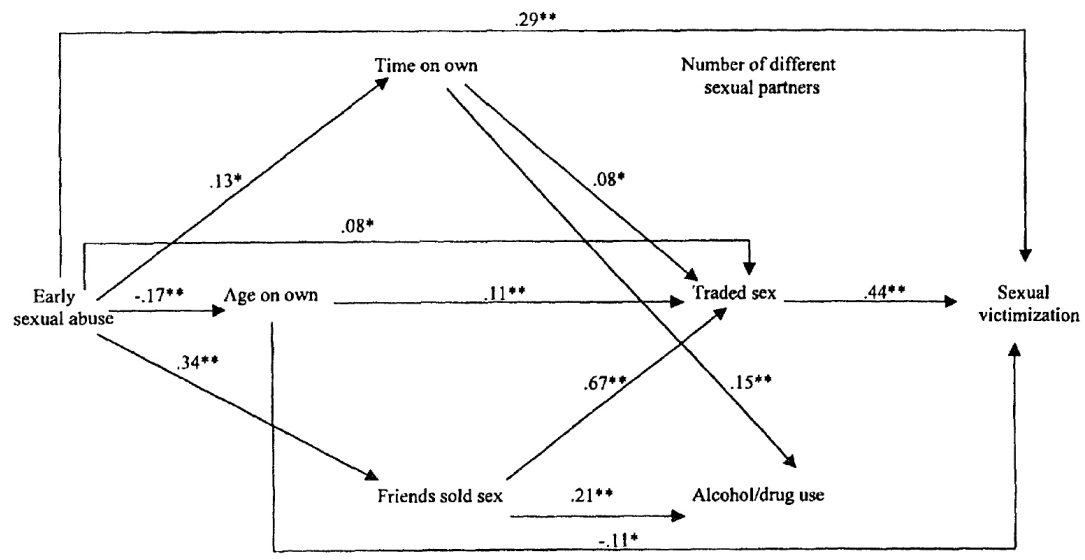

Figure 2. Path Model for Female Sexual Victimization Note: Only significant paths shown. $R^{2}=.39,{ }^{*} p<.05 .{ }^{* *} p<.01$.

The results of the path model for sexual victimization among female homeless and runaway adolescents are shown in Figure 2 (only significant paths shown). The model revealed that early sexual abuse was positively associated with time on own, indicating that young women from sexually abusive family backgrounds were likely to have spent a greater portion of their time on the streets or in unsupervised living arrangements $(\beta=.13)$ compared to their nonabused counterparts. Early sexual abuse negatively affected age on own $(\beta=-.17)$, suggesting that adolescents with a history of sexual abuse were more likely to have run at earlier ages as a result of the abuse. A history of sexual abuse also was positively associated with friends selling sex $(\beta=.34)$ and sex trading $(\beta=.08)$, indicating that young women who were previously sexually abused were more likely to have affiliated with friends who sold sex and to have engaged in trading sex for food, shelter, money, and/or drugs. Early sexual abuse also had a direct positive effect on sexual victimization $(\beta=.29)$, indicating that young women from abusive family backgrounds were more likely to have reported being sexually victimized on the street.

Age on own positively predicted sex trading $(\beta=.11)$, suggesting that older adolescents were more likely to have traded sex for food, shelter, money, and/or drugs compared to their younger counterparts. Further- 
Table 2. Standardized Regression Coefficients for Female Sexual Victimization $(N=333)$

\begin{tabular}{|c|c|c|c|c|c|c|c|}
\hline Variable & $\begin{array}{c}\text { Age } \\
\text { on Own }\end{array}$ & $\begin{array}{l}\text { Time } \\
\text { on Own }\end{array}$ & $\begin{array}{l}\text { Friends } \\
\text { Sold Sex }\end{array}$ & $\begin{array}{l}\text { Different } \\
\text { Sex Partners }\end{array}$ & $\begin{array}{l}\text { Traded } \\
\text { Sex }\end{array}$ & $\begin{array}{l}\text { Alcohol/ } \\
\text { Drug Use }\end{array}$ & $\begin{array}{c}\text { Sexual } \\
\text { Victimization }\end{array}$ \\
\hline Early sexual abuse & $-.17^{* *}$ & $.13^{*}$ & $.34^{* *}$ & .10 & $.08^{*}$ & -.01 & $.29^{* *}$ \\
\hline Age on own & & -.05 & .02 & .06 & $.11^{* *}$ & -.01 & $-.11^{*}$ \\
\hline Time on own & & & & .09 & $.08^{*}$ & $.15^{* *}$ & .06 \\
\hline Friends sold sex & & & & .06 & $.67^{* *}$ & $.21^{* *}$ & -.04 \\
\hline Different sex partne & ers & & & & & & -.02 \\
\hline Traded sex & & & & & & & $.44^{* *}$ \\
\hline Alcohol/drug use & & & & & & & .07 \\
\hline$R^{2}$ & .03 & .02 & .12 & .03 & .53 & .08 & .39 \\
\hline
\end{tabular}

${ }^{*} p<.05 ;{ }^{* *} p<.01$.

more, age on own negatively affected sexual victimization $(\beta=-.11)$, indicating that the earlier adolescents find themselves on the street, the greater the likelihood is of being sexually victimized. Spending more time out on their own increased the likelihood of these adolescents trading sex $(\beta=$ .08). In addition, young women who spent more time out on their own reported higher rates of alcohol and/or drug use $(\beta=.15)$.

Friends selling sex was strongly associated with adolescents trading sex $(\beta=.67)$ and alcohol and/or drug use $(\beta=.21)$. Finally, sex trading was positively associated with sexual victimization $(\beta=.44)$, suggesting that young women who had traded sex for food, shelter, money, and/or drugs were more likely to have been sexually victimized compared to those who had not engaged in such behaviors. The model for female sexual victimization explained 39\% of the variance (see Table 2 for all the standardized regression coefficients).

The decomposition of the effects of independent variables on the dependent variables (Jöreskog \& Sörbom, 1993) are presented in Table 3. The results indicated that although sexual abuse had a direct effect on sexual victimization, it also had indirect effects. That is, sexual abuse indirectly affected sexual victimization via age on own, time on own, friends selling sex, and trading sex. The effects of time on own and friends selling sex on sexual victimization were all indirect through trading sex. Young women who had friends who sold sex were more likely to have engaged in survival sex that resulted in their being sexually victimized. 
Table 3. Decomposition of Effects for Female Sexual Victimization $(N=333)$

\begin{tabular}{|c|c|c|c|c|c|c|c|}
\hline Variable & $\begin{array}{c}\text { Age } \\
\text { on Own }\end{array}$ & $\begin{array}{c}\text { Time } \\
\text { on Own }\end{array}$ & $\begin{array}{l}\text { Friends } \\
\text { Sold Sex }\end{array}$ & $\begin{array}{c}\text { Different } \\
\text { Sex Partners }\end{array}$ & $\begin{array}{l}\text { Traded } \\
\text { Sex }\end{array}$ & $\begin{array}{l}\text { Alcohol/ } \\
\text { Drug Use }\end{array}$ & $\begin{array}{c}\text { Sexual } \\
\text { Victimization }\end{array}$ \\
\hline \multicolumn{8}{|c|}{ Early sexual abuse } \\
\hline Direct & $-.17^{* *}$ & $.13^{*}$ & $.34^{* *}$ & .10 & $.08^{*}$ & -.01 & $.29^{* *}$ \\
\hline Indirect & .00 & .01 & .00 & .02 & $.22^{* *}$ & $.09^{* *}$ & $.15^{* *}$ \\
\hline Total & $-.17^{* *}$ & $.14^{*}$ & $.34^{* *}$ & $.13^{*}$ & $.30^{* *}$ & .09 & $.44^{* *}$ \\
\hline \multicolumn{8}{|c|}{ Age on own } \\
\hline Direct & & -.05 & .02 & .06 & $.11^{* *}$ & -.01 & $-.11^{*}$ \\
\hline Indirect & & .00 & .00 & .00 & .01 & .00 & .05 \\
\hline Total & & -.05 & .02 & .05 & $.12^{*}$ & -.01 & -.07 \\
\hline \multicolumn{8}{|c|}{ Time on own } \\
\hline Direct & & & & .09 & $.08^{*}$ & $.15^{* *}$ & .06 \\
\hline Indirect & & & & .00 & .00 & .00 & $.04^{*}$ \\
\hline Total & & & & .09 & $.08^{*}$ & $.15^{* *}$ & $.10^{*}$ \\
\hline \multicolumn{8}{|c|}{ Friends sold sex } \\
\hline Direct & & & & .06 & $.67^{* *}$ & $.21^{* *}$ & -.04 \\
\hline Indirect & & & & .00 & .00 & .00 & $.31^{* *}$ \\
\hline Total & & & & .06 & $.67^{* *}$ & $.21^{* *}$ & $.27^{* *}$ \\
\hline \multicolumn{8}{|c|}{ Different sex partners } \\
\hline Direct & & & & & & & -.02 \\
\hline Indirect & & & & & & & .00 \\
\hline Total & & & & & & & -.02 \\
\hline \multicolumn{8}{|l|}{ Traded sex } \\
\hline Direct & & & & & & & $.44^{* *}$ \\
\hline Indirect & & & & & & & .00 \\
\hline Total & & & & & & & $.44^{* *}$ \\
\hline \multicolumn{8}{|c|}{ Alcohol/drug use } \\
\hline Direct & & & & & & & .07 \\
\hline Indirect & & & & & & & .00 \\
\hline Total & & & & & & & .07 \\
\hline
\end{tabular}

${ }^{*} p<.05,{ }^{* *} p<.01$.

\section{Discussion}

Consistent with previous research (Whitbeck et al., 1997a; Whitbeck et al., 1999; Whitbeck \& Simons, 1990), our results indicated that those with a history of sexual abuse were likely to be revictimized on the street. The effects of early sexual abuse were found to have both direct and indirect effects on street sexual victimization. In terms of direct effects, given the fact that many adolescents who experience sexual abuse within the home are likely to suffer psychological and emotional problems (Beitchman et al., 1991), it is 
possible that they bring these problems to the street, thereby making them vulnerable targets, easily preyed on by potential offenders. As such, the effects of early sexual abuse in combination with the social context of street life are likely to put these young women at increased risk for sexual victimization on the street. The indirect effects are consistent with risk amplification (Whitbeck et al., 1997a) in that adolescents are likely to leave home at an early age due to sexual abuse and to associate with deviant peers upon entering the street environment. Consistent with this perspective and victimization theories (Cohen \& Felson, 1979; Hindelang et al., 1978), spending time on the street and engaging in high-risk behaviors puts these young people in threatening situations. Close proximity to potential offenders exposes these youth to crime and criminals thereby increasing the risk for victimization. In particular, the combination of early emotional and psychological problems and the high-risk environment in which these adolescents interact on a daily basis results in an increased risk for sexual victimization. Although substance use and number of different sexual partners were significantly associated with sexual victimization at the bivariate level, these associations are not significant when simultaneously controlling for the effects of all the other variables. Both substance use and number of different sexual partners are highly correlated with sex trading, which accounts for much of the variation in sexual victimization.

Some limitations should be noted in this study. The use of cross-sectional data does not allow us to test causal interpretations and limits the strength of our argument regarding the amplification of effects. However, the intervening variables, which represent street experiences, have significant effects for young women's risk for sexual victimization and are consistent with the hypothesized relationships. Another limit is the use of adolescent self-reports. Because the information was provided by the adolescent only, it is difficult to determine the extent of potential bias. However, research comparing runaway youth and parent reports has found that these youth do not appear to be overreporting abuse in the home (Whitbeck, Hoyt, \& Ackley, 1997b). Another limitation is the retrospective nature of some of the measures. For example, time on own required adolescents to think back to all the times they had been on the street or in unsupervised living arrangements. It is likely that some young people may not have been able to recall every instance they were on the street or the actual duration of each stay. Finally, the term sexual activity was not defined for the adolescents in the questions dealing with early sexual abuse; therefore, the definition was left up to the interpretation of each respondent.

Notwithstanding these concerns, the results have practical implications for those who work with homeless and runaway adolescents. Foremost is 
the fact that many of these young women have experienced early sexual abuse in the home at the hands of a parent or guardian. Policies that require runaways to return home only put these youth at further risk for future victimization. A second policy implication deals with life on the streets for these adolescents. Associating with deviant peers and participating in deviant behaviors increase risk for victimization. The pattern of exploitation and victimization within the family and on the streets has serious and cumulative developmental consequences. Early interception and intervention through increased funding for safe-houses, drop-in centers, and especially for street-based outreach workers is needed for runaways to break this cycle. In terms of future research, it may be helpful to determine who is sexually victimizing these young women on the street. Research demonstrates that associating with deviant peer groups increases the adolescents' chances of engaging in deviant, risky subsistence strategies (Hagan \& McGarthy, 1997; Whitbeck et al., 1999), and such behaviors increase the risk for victimization (Lauritsen, Sampson, \& Laub, 1991). Determining whether deviant peers, strangers, or both are sexually victimizing these young women may be important information for streetbased outreach workers when determining what course of action should be taken when dealing with victims of sexual victimization. In summary, young women who leave dysfunctional and disorganized families to escape the abuse often find themselves faced with similar problems once they enter the street environment. Plagued by financial problems such as lack of food and shelter, these young adolescents become vulnerable to the dangers of survival in an often hostile and exploitative street environment. Existing in such an environment increases these young women's chances of being revictimized time and time again.

\section{References}

Bagley, C., \& Young, L. (1987). Juvenile prostitution and child sexual abuse: A controlled study. Canadian Journal of Community Mental Health, 6, 5-26.

Bayatpour, M., Wells, R. D., \& Holford, S. (1992). Physical and sexual abuse as predictors of substance use and suicide among pregnant teenagers. Journal of Adolescent Health, 13, 128-132.

Becker, J. V. (1988). The effects of child sexual abuse on adolescent sexual offenders. In G. E. Wyatt \& G. J. Powell (Eds.), Lasting effects of child sexual abuse (pp. 193-207). Newbury Park, CA: Sage.

Beitchman, J. H., Zucker, K. J., Hood, J. E., da Costa, G. A., \& Akman, D. (1991). A review of the short-term effects of child sexual abuse. Child Abuse \& Neglect, 15, 537-556.

Beitchman, J. H., Zucker, K. J., Hood, J. E., da Costa, G. A., Akman, D., \& Cassavia, E. $(1992)$. A review of the long-term effects of child sexual abuse. Child Abuse $\mathcal{E}$ Neglect, 16, 101-118. 
Browne, A,, \& Finkelhor, D. (1986). Impact of child sexual abuse: A review of the research. Psychological Bulletin, 99, 66-77.

Cohen, L. E., \& Felson, M. (1979). Social change and crime rate trends: A routine activity approach. American Sociological Review, 44, 588-608.

Dembo, R., Williams, L., LaVoie, L., Berry, E., Getreu, A., Wish, E. D., Schmeidler, J., \& Washburn, M. (1989). Physical abuse, sexual victimization, and illicit drug use: Replication of a structural analysis among a new sample of high-risk youths. Violence and Victims, 4, 121-138.

Elder, G. (1997). Life course and human development. In R. Lerner (Ed.), Handbook of child psychology: Vol. 1. Theoretical models of human development (pp. 939-991). New York: Wiley.

Finkelhor, D. (1984). Child sexual abuse: New theory and research. New York: Free Press.

Finkelhor, D. (1993). Epidemiological factors in the clinical identification of child sexual abuse. Child Abuse \& Neglect, 17, 67-70.

Finkelhor, D. (1994). Current information on the scope and nature of child sexual abuse. The Future of Children, 4, 31-53.

Finkelhor, D., \& Dziuba-Leatherman, J. (1994). Children as victims of violence: A national survey. Pediatrics 94, 413-420.

Fleming, J., Mullen, P., \& Bammer, G. (1997). A study of potential risk factors for sexual abuse in childhood. Child Abuse \& Neglect, 21, 49-58.

Hagan, J., \& McCarthy, B. (1997). Mean streets: Youth crime and homelessness. New York: Cambridge University Press.

Hindelang, M. J., Gottfredson, M. R., \& Garofalo, J. (1978). Victims of personal crime: An empirical foundation for a theory of personal victimization. Cambridge, MA: Ballinger.

Janus, M., McCormack, A., Burgess, A. W., \& Hatman, C. (1987). Adolescent runaways: Causes and consequences. Lexington, MA: Lexington Books.

Jöreskog, K., \& Sörbom, D. (1993). LISREL 8: User's reference guide. Chicago: Scientific Software.

Kellogg, N. D., \& Hoffman, T. J. (1997). Child sexual revictimization by multiple perpetrators. Child Abuse \& Neglect, 21, 953-964.

Lauritsen, J. L., Sampson, R. J., \& Laub, J. H. (1991). The link between offending and victimization among adolescents. Criminology, 29, 265-291.

McCarthy, B., \& Hagan, J. (1992). Surviving on the street: The experiences of homeless youth. Journal of Adolescent Research, 7, 412-430.

McCormack, A., Janus, M., \& Burgess, A. W. (1986). Runaway youths and sexual victimization: Gender differences in an adolescent runaway population. Child Abuse $\&$ Neglect, 10, 387-395.

Morrow, K. B., \& Sorell, G. T. (1989). Factors affecting self-esteem, depression, and negative behaviors in sexually abused female adolescents. Journal of Marriage and the Family, 51, 677-686.

Patterson, G. R. (1982). Coercive family processes. Eugene, OR: Castilia.

Patterson, G. R., DeBaryshe, B. D., \& Ramsey, E. (1989). A developmental perspective on antisocial behavior. American Psychologist, 44, 329-335.

Patterson, G. R., Dishion, T. J., \& Bank, L. (1984). Family interaction: A process model of deviancy training. Aggressive Behavior, 10, 253-267.

Peters, S. D. (1988). Child sexual abuse and later psychological problems. In G. E. Wyatt \& G. J. Powell (Eds.), Lasting effects of child sexual abuse (pp. 101-117). Newbury Park, CA: Sage. 
Silbert, M. H., \& Pines, A. M. (1981). Sexual child abuse as an antecedent to prostitution. Child Abuse E Neglect, 5, 407-41 1.

Simons, R. L., \& Whitbeck, L. B. (1991). Sexual abuse as a precursor to prostitution and victimization among adolescent and adult homeless women. Journal of Family Issues, $12,361-379$.

Weisberg, D. K. (1985). Children of the night: A study of adolescent prostitution. Lexington, MA: Lexington Books.

Whitbeck, L. B., Hoyt, D. R., \& Ackley, K. A. (1997a). Abusive family backgrounds and later victimization among runaway and homeless adolescents. Journal of Research on Adolescence, 7, 375-392.

Whitbeck, L. B., Hoyt, D. R., \& Ackley, K. A. (1997b). Families of homeless and runaway adolescents: A comparison of parent/caretaker and adolescent perspectives on parenting, family violence, and adolescent conduct. Child Abuse E Neglect, 21, 517-528.

Whitbeck, L. B., Hoyt, D. R., \& Yoder, K. A. (1999). A risk-amplification model of victimization and depressive symptoms among runaway and homeless adolescents. American Journal of Community Psychology, 27, 273-296.

Whitbeck, L. B., \& Simons, R. L. (1990). Life on the streets: The victimization of runaway and homeless adolescents. Youth \& Society, 22, 108-125.

Whitbeck, L. B., \& Simons, R. L. (1993). A comparison of adaptive strategies and patterns of victimization among homeless adolescents and adults. Violence and Victims, $8,135-152$.

Widom, C. S., \& Kuhns, J. B. (1996). Childhood victimization and subsequent risk for promiscuity, prostitution, and teenage pregnancy: A prospective study. American Journal of Public Health, 86, 1607-1612.

Kimberly A. Tyler is an assistant professor in sociology at the University of Central Florida. Her research interests include sexual risk-taking behaviors, sexual abuse, and sexual victimization among homeless and runaway adolescents.

Dan R. Hoyt is a professor of sociology at Iowa State University and a faculty affiliate at the Institute for Social and Behavioral Research. His current research interests include the mental health impacts of early life trauma, substance abuse, and adolescent victimization.

Les B. Whitbeck is a professor of sociology at Iowa State University and a faculty affiliate at the Institute for Social and Behavioral Research. His research focuses on runaway and homeless adolescents and other high-risk adolescent behaviors. 